\title{
O prazer pelo fazer: a conexão corporal na identidade jogador-avatar
}

\section{Rikke Toft Nørgård}

Doutora; Aarhaus University, Aarhaus, Dinamarca

rtoft@tdm.au.dk

Tradução: Mayara Caetano

Universidade Federal do Rio Grande do Sul, Porto Alegre, RS, Brasil; University of Turku, Turku, Finlândia mayarcae@gmail.com

Revisão de Tradução: Gabriela Kurtz

Pontifícia Universidade Católica do Rio Grande do Sul, Porto Alegre, RS, Brasil

Universidade Federal do Rio Grande do Sul

gabriela@sidicom.com.br

\section{Resumo}

Este artigo trata sobre a relação entre jogadores e avatares, tendo como base a corporalidade, locomotividade e a habilidade artesanal. Para tanto, a fenomenologia de Merleau-Ponty é utilizada como base teórica, assim como, adaptações de frameworks de outros autores, como a locomoção corpórea de Sheets-Johnstone e a habilidade artesanal de Sennet. Pesquisas anteriores sobre a identidade jogador-avatar são discutidas e categorizadas em: visualidade, cognição, dramaturgia, prótese e sociabilidade, explicando cada uma. Posteriormente, a tais categorias serão reintroduzidas tendo como perspectiva o viés corpóreo, de forma a desenvolver novos sentidos e contrapontos, apresentados como: corporalidade digital (esquema corpóreo e perspectiva visual); locomoção e memória corporal; digital corporalidade e incorporação; extensão corporal; e o prazer pelo fazer. Por fim, esse artigo reflete sobre a importância da adoção dessas novas estruturas para se obter uma perspectiva mais completa da identidade jogador-avatar e escapar do imperialismo teórico.

\section{Palavras-chave}

Avatar. Corporalidade. Habilidade artesanal. Fenomenologia.

Filosofia do corpo. 


\section{Introdução}

0 presente artigo se propõe a investigar a relação entre jogadores e avatares com base em três dimensões geralmente desconsideradas dentro das pesquisas sobre a identidade jogadores-avatares: corporalidade, locomotividade e habilidade artesanal ${ }^{1}$. Isso é feito com a função de estabelecer uma conexão corporal na identidade jogador-avatar; uma conexão que está completamente fundamentada na fusão, daquilo que nomeio como, digital corporalidade (o corpo digital e a interação) e corporalidade digital (o corpo material e a interação). Desse modo, a identidade jogador-avatar é, em grande medida, algo que vem junto e é apreciado pela interação corpórea-locomotiva dos jogadores. Ao destacar a conexão corpórea na identidade de jogadores-avatares como uma fusão da digital corporalidade e a corporalidade digital, o artigo afirma que, na identidade jogador-avatar são os avatares que estão sendo incorporados dentro do esquema corpóreo dos jogadores, ao invés dos jogadores serem prolongamentos protéticos para os avatares; isso significa que a relação e identificação é caracterizada por uma corporalidade centrípeta, ao invés de centrífuga. Consequentemente, o artigo defende uma conexão corpórea como central na (pesquisa sobre) identidade jogador-avatar, e que, os jogadores e os avatares estão unidos no prazer pelo fazer ${ }^{2}$ obtido através da experiência de presença em primeira mão, da perspectiva em primeira mão e da imersão em primeira mão, estejam os jogadores jogando em primeira pessoa como em Borderlands (Gearbox Software, 2009); no jogo Massivo Multiplayer Online Gaming (MMOG) em terceira pessoa como World of Warcraft (também conhecido como WoW, da Blizzard, 2004); ou em um 'exergame' ${ }^{3}$ como Move: Start the Party (Supermassive Games, 2010).

Como corrente teórica, esse artigo é conduzido pelo trabalho de Maurice MerleauPonty em Fenomenologia da Percepção (1999), assim como, os esclarecimentos modernos dos conceitos chave: esquema corpóreo e imagem corporal. Entretanto, ao invés de instituir

\footnotetext{
${ }^{1}$ Nota de tradução: 0 termo original craftsmanship, de Richard Sennet (orig. 2008), foi traduzido para o português brasileiro pelo tradutor da obra, Clóvis Marques - como habilidade artesanal. Segue o trecho da tradução da obra com a definição: "A expressão 'habilidade artesanal' pode dar a entender um estilo de vida que desapareceu com o advento da sociedade industrial - o que, no entanto, é enganoso. Habilidade artesanal designa um impulso humano básico e permanente, o desejo de um trabalho benfeito por si mesmo. Abrange um espectro muito mais amplo que o trabalho derivado de habilidades manuais; diz respeito ao programa de computador, do médico, do artista; os cuidados paternos podem melhorar quando são praticados como uma atividade bem capacitada assim como a cidadania. Em todos esses terrenos, a habilidade artesanal está centrada em padrões objetivos, na coisa em si mesma." (SENNET, 2009, p.19)

${ }^{2}$ Nota de tradução: No original, o termo utilizado é "joy of doing" e aqui será adaptado para "o prazer pelo fazer", assim como, feito com o título do artigo. Entendemos que essa aproximação está de acordo com os conceitos e filiações teóricas utilizadas pela autora no original em inglês.

${ }^{3}$ Nota de tradução: Esses são jogos voltados para a atividade física em um ambiente virtualizado.
} 
uma investigação puramente Merleau-Pontiana, o artigo procura, notavelmente, através da adaptação de framework (esquema) para locomoção corpórea (Maxine Sheets-Johnstone, The Primacy of Movement, 1999), interação corpórea com a digitalidade (Mark B.N. Hansen, Bodies in Code, 2006) e incorporação da habilidade artesanal (kin)estética (Richard Sennet, O Artíficie, 2009), para elucidar, os modos pelos quais, a identidade jogador-avatar é fundamentada e expressa por si mesma através da corporalidade, locomotividade e habilidade artesanal. Além disso, esses esquemas podem nos ajudar a esclarecer como "a conexão corpórea" se destaca se comparada ao esquema padrão da identidade de jogadoravatar dentro das pesquisas em jogos.

No entanto, gostaria de primeiramente de definir o cenário com a pequena descrição de como essa conexão corpórea se desdobra em um ataque surpresa em WoW. Abaixo, está uma tentativa de apreender a conexão com o avatar baseando se na fusão da corporalidade digital e digital corporalidade dos jogares. Isso é feito através da justaposição de campos de descrição focando na locomotividade corporal dos jogadores com gravações de vídeo das mãos corporais (físicas) em ação no jogo e capturas dos avatares em ação:

O avatar permanece imóvel enquanto as mãos do jogador estão repousadas sob o teclado e o mouse ao passo que o grupo de ataque planeja e alinha suas interações corpóreas através da comunicação ante de começarem a emboscada. Depois de um tempo, as mãos inquietas começam a fazer o avatar pular de um lado para o outro e dançar em frente dos avatares dos membros do grupo. Muitos membros do grupo seguem o exemplo uma vez que esperam impacientemente para lançar se na intensa locomoção corpórea da instância de ataque. Finalmente, o líder da emboscada convoca a interação corpórea: '3-2-1-Vai' e instantaneamente os dedos da mão esquerda começam a dançar pelo teclado enquanto a mão direita desliza com o mouse e clica em seus botões. Ondas rítmicas de toques no teclado e cliques de mouse ascendem como uma música orquestrada corporalmente: '1-1-1-1-2-2-22-2-clique-clique-clique-clique'. As mãos dos jogadores dançam ao redor em um quadrado no terço esquerdo do teclado - para cima e para baixo, para dentro e para fora, se aproximando e se afastando assim como uma aranha em uma luta de morte, ou freneticamente girando em uma teia complicada e caótica. É como se a vida e a morte dependessem da performance deles enquanto a mão esquerda dança sua distinta 'dança quadrangular' ao passo que, a outra mão anda com o mouse e compõe o seu 'cliquecliqueclique' musical continuo. Em nenhum momento os olhos são removidos das interações na tela, pois monitoram atentamente a corporeidade digital dos outros membros do grupo na tentativa de, por meio de intensa interação corporal, manter a saúde dos outros membros do grupo elevada. Simultaneamente, as mãos incessantemente entrelaçam o digital e a corporalidade como interações locomotivas visuais e digitais criadas através da locomoção corpórea. Os dedos dos jogadores dançam entre as teclas WASD e as teclas de feitiços espalhadas ao redor no terço esquerdo do teclado enquanto a digitalidade na tela explode em informações desordenadas, barras, caixas, números e ícones, sons de golpes e locomoção digital enquanto o jogo reage digitalmente as interações corpóreas dos jogadores e a reação corpórea dos jogadores a interação digital do jogo. Essa é a habilidade artesanal em alto nível enquanto o jogador incessantemente e competentemente funde jogador-como-avatar com avatarcomo-jogador através das danças manuais no ritmo do ataque, sabendo que se eles forem pegos fora do padrão por apenas um segundo o grupo provavelmente será destruído. 


\section{Pesquisas anteriores: construções permeáveis da identidade dos jogadores-avatares}

Como uma leitura sintomática da conexão avatariana nas pesquisas sobre jogos, os cinco parágrafos que seguem irão oferecer uma apresentação condensada sobre várias construções impregnadas dentro de pesquisas anteriores de jogadores-avatares. Quando pesquisadores de jogos exploraram a relação entre jogadores e avatares as suposições sobre a natureza da conexão avatariana foram múltiplas. Entretanto, alguns padrões recorrem em relação ao modo pelo qual essa conexão é concebida. Pesquisas em jogos sobre a conexão avatariana podem, portanto, de acordo com os termos centrais aplicados, grosso modo, ser dividido nas cinco proposições que seguem:

\subsection{Visualidade: identidade jogador-avatar como imagem corporal e perspectiva visual}

Aqui, jogadores são construídos como preceptores visuais, observadores ou espectadores que monitoram ou percebem a saída visual das telas. Jogadores identificam se com avatares como sendo imagens corporais exteriorizadas ou duplicadas. Consequentemente "o gênero (tipo) de jogos como Misty ou Doom remediam o cinema, e tais jogos são às vezes chamados de 'filmes interativos'” (Bolter e Grusin, 2000, p. 47). Novas adaptações desse posicionamento podem ser encontradas, por exemplo em Bob Rehak 'Playing at Being: Psycoanalysis and the Avatar' (2003) em que é demonstrado que:

[...] espectador é claramente central para a forma. Conforme nós jogamos, nós observamos a nós mesmos jogando [...]. Portanto, é mais preciso, ou pelo menos inclusivo, falar sobre a conexão avatariana: uma 'estrutura de visualização' na qual o sujeito, agindo no seu desejo de ver a si mesmo e o outro, busca sua reflexão no imaginário assim como um gato persegue seu rabo. (REHAK, 2003, pp. 118-119)

E Miroslaw Filiciak 'Hiperidentities: Postmodern Identity Patterns in Massive Multiplayer Online Role-Playing Games' (2003) na qual ela menciona que: “uma vez que nossas ações são visíveis em telas de televisores e computadores, é aonde nós realmente agimos [...] Hoje, o espelho é substituído pela tela" (FILICIAK, 2003, p. 100) na qual 
jogadores fazem "um fetiche; nós desejamos isso, não apenas nós queremos olhar as telas, mas também sermos 'olhados' nela" (ibidem, 2003, p. 99). Portanto, a identidade jogadoravatar é controlada em estruturas de visão e visualidade, enquanto a relação é construída através de termos como "aparência", "imagem de tela", "corpo espetacular", "reflexo", "espelho", "contemplação", "representação visual em tela" e "projeção". Fazendo uma provocação, esse posicionamento constrói a identidade jogador-avatar como uma relação voyeurística onde jogadores são imersos em uma visualização e monitoramento de suas próprias reflexões avatarianas espelhadas em tela.

\subsection{Cognição: identidade jogador-avatar como mentes projetadas e intencionalmente transmitidas}

Aqui, jogadores são construídos como um tipo de pensadores cognitivos, mentes incorporadas, interpretes ou fabricantes de significados projetando suas mentes em ou transmitindo cognição para o avatar no espaço digital. Jogadores se identificam com avatares como se eles pensassem com eles, dentro deles, como eles ou através deles. Esse "pensar através, em, com ou como máquinas" é como N. Katherine Hayles aponta em 'How We Became Post-Human' (1999) uma tradição de longa data dentro, por exemplo de tecnologias da informação, cibernética, computação simulada, e ciência cognitiva que "procede primeiramente ao longo das linhas que procuravam compreender os seres humanos como um conjunto de processos informacionais" (HAYLES, 1999, p. 4) porque "informação é em algum sentido mais essencial, mais importante e mais fundamental do que a materialidade" (ibidem, 1999, p. 18). Uma adaptação da relação de jogadores-avatares como consistindo de um pensamento com avatares é, por exemplo, encontrado em Constance Steinkuehler 'Massive Multiplayer Online Games as an Educational Technology: An Outline for Research' (2008) na qual ela: “documenta e analisa essas práticas centrais que constituem gameplay em mundos virtuais" (STEINKUEHLER, 2008, p. 10). Essas práticas centrais são enumeradas por ela como: "formas complexas de cognição social e materialmente distribuídas"; "práticas colaborativas de resolução de problemas"; "práticas de instrução narrativa"; "hábitos mentais científicos"; "instrução computacional"; e "inteligência coletiva" (ibidem, 2008, pp. 12-13). Uma adaptação de pensar em ou como 
avatares é encontrada, por exemplo, em James Paul Gee 'Videogames and Embodiment' (2008) no qual a identidade de jogador-avatar é definida como uma relação de projeção cognitiva: "Essa natureza dual dos personagens de jogos - que eles são projetos (cognitivos) que foram entregues aos jogadores e serem o que os jogadores projetam seus desejos, intenções e objetivos - é por isso, que eu me refiro a eles como seres projetivos" (GEE, 2008, p. 260). Finalmente, uma adaptação do pensar através dos avatares é encontrada, por exemplo, em Anders Gregersen e Torben Grodal 'Embodiment and Interface' (2009) onde avatares são utilizados como meios para executar as intencionalidades cognitivas dos jogadores na esfera digital, dado que "a corporificação mental é o que o organismo faz" (GREGERSEN; GRODAL, 2009, p. 66) e "videogames são atividades suportadas por computadores-e-monitores que selecionam uma pequena cesta cheia de toda maneira possível que os outros cérebros corporificados podem se relacionar com os mundos e outros agentes" (GREGERSEN; GRODAL, 2009, p. 81). Aqui, avatares tornam-se mentes corporificadas dos jogadores que são utilizadas para realizar as intenções e os objetivos cognitivos dos mesmos no espaço digital. Dentro desse posicionamento, a identidade de jogadores-avatares é vista como algo que os jogadores pensam com (por exemplo, avatares são ferramentas cognitivas dos jogadores), pensam em (por exemplo, avatares são containers para as mentes dos jogadores), pensados como (por exemplo, avatares tornam se as "novas mentes" dos jogadores) ou pensados através (por exemplo, avatares são "cabos" através das quais os jogadores transmitem suas intencionalidades). Fazendo uma provocação, esse posicionamento constrói a identidade de jogadores-avatares com uma relação de mentalismo onde jogadores são imersos na projeção, transmissão ou transporte para avatares como mentes corporificadas.

\subsection{Dramaturgia: identidade jogador-avatar como role-play, presença e performance}

Aqui, os jogadores são construídos como narradores, protagonistas, personagens ou atores projetados, ou personagens ficcionais encenados em um mundo fictício. Os jogadores se identificam com os avatares enquanto eles vivem através da interação digital como os avatares e com os avatares. Nas palavras de Branda Laurel "pessoas que estão participando 
da representação já não são mais membros da audiência. Não é que a audiência se junte com os atores no palco, é que eles se tornam atores" (LAUREL, 1991, p. 17, ênfase no original). Novas adaptações são encontradas por exemplo em Kjetil Sandvik 'In and Out of Character: Complex Role-Play and Dramaturgy in an Online World' (2006) onde: “o papel desempenhado pelo participante é que é: personagem fictício" (SANDVIK, 2006, p. 15). e Andrew Burn 'Playing Roles' (2006) argumentando que: “É por meio do avatar que o jogador se torna corporificado no jogo e performa o papel de protagonista" (BURN, 2006, p. 72) e vivenciam "identificação com um personagem ficcional" (ibidem, 2006, p. 83). Por isso, a identidade jogador-avatar se torna fechada dentro de estruturas dramatúrgicas caracterizadas por termos como "storytellers" (contadores de histórias ou narradores), "protagonistas" e "atores" para jogadores; "máscaras" (ficcionais)", "personagens ficcionais" e "identidades ficcionais" para avatares; "actantes", "pretendentes" ou "role playing" para as interações; e "palco", "ciberdrama", "estrutura dramática" e "ficção dramática" para as atividades, resumindo alguns dos termos centrais de vários trabalhos com essa perspectiva. Fazendo uma provocação, a identidade jogador-avatar é construída como uma relação de escapismo em que jogadores estão imersos no role-playing ou performance dos avatares com personagens ficcionais.

\subsection{Próteses: identidade jogador-avatar como protética, extensão} corporal e ferramentas extensoras

Aqui, jogadores são construídos como extensores de seus corpos para os avatares como ferramentas protéticas, veículos, marionetes ou dublês corporais. Jogadores se identificam com avatares enquanto eles proteticamente estendem eles mesmos aos avatares (servindo como corpos protéticos) ou remotamente controlando avatares como titereiros puxando cordas de uma marionete ou habitando eles de dentro como um motorista em um veículo. Esse argumento também pode ser caracterizado por uma das mais influentes sentenças de Donna Haraway em 'Manifesto Ciborgue' (2009): “Nossas máquinas são perturbadoramente vivas e nós mesmos assustadoramente inertes (HARAWAY, 2009, p. 42) implicando que: 


\begin{abstract}
Não existe, em nosso conhecimento formal, nenhuma separação fundamental, ontológica, entre máquina e organismo, entre técnico e orgânico [...] Por que, na melhor das hipóteses, devemos nos limitar a considerar como corpos, além dos humanos, apenas outros seres também envolvidos pela pele? [...] as máquinas podem ser dispositivos protéticos, componentes íntimos, amigáveis eus. Não precisamos do holismo orgânico [...] (HARAWAY, 2009, pp. 91-92).
\end{abstract}

Novas adaptações podem ser encontradas, por exemplo, em Martti Lahti 'As We Become Machines: Corporealized Pleasures in Video Game' (2003) apontando que: "muito do desenvolvimento dos videogames foi conduzido pelo desejo por imersão corporal com tecnologia, uma vontade de envolver o jogador na tecnologia" (LAHTI, 2003, p. 159) e que “jogos comodificam nossos desejos ciborgues, nossa vontade de se fundir e se tornar tecnologia [...] nossos corpos têm que desenvolver um tipo de memória protética como se nós (nossos avatares) devemos sobreviver enquanto nos fundimos com os mundos eletrônicos" (LAHTI, 2003, p. 166) e Kathy Cleland 'Prosthetic Bodies as Virtual Cyborgs' (2010) dizendo que "nossas extensões protéticas tecnológicas nos permitem amplificar e estender a nós mesmos" (CLELAND, 2010, p. 75). Portanto, a identidade jogador-avatar, se torna um alongamento dos jogadores para os avatares através das próteses. Uma postura focada em termos como "visão protética", "corpos substitutos", "re-corporificação protética", "corpo avatar protético", "instrumentos", "veículos" e "marionetes". Fazendo uma provocação, esse posicionamento constrói a identidade jogador-avatar como uma relação de extensão ciborgue em que jogadores são imersos em tecnologias protéticas e avatares.

\title{
2.5 Sociabilidade: identidade jogador-avatar como auto representação e jogo de identidade
}

Aqui, jogadores são construídos como indivíduos engajados culturalmente e socialmente em auto representação ou em jogo de identidade através de seus avatares. Jogadores se identificam com avatares enquanto eles performam e constroem avatares como sua própria autoimagem. Como diz Sherry Turkle, quando fala sobre MUD’s que: “a Internet converteu-se num laboratório social significativo para a realização de experiências com as construções e reconstruções do eu que caracterizam a vida pós-moderna. Na sua realidade virtual, moldamo-nos e criamo-nos a nós mesmos." (TURKLE, 1997: 265). Novas adaptações desse ponto de vista são encontradas por exemplo em Miroslaw Filiciak 'Hyperidentities: 
Postmodern Identity Patterns in Massive Multiplayer Online Role-Playing Games' (2003) dizendo que: “a identidade virtual então torna-se um dos muitos 'eus' incluídos na identidade do usuário" (FILICIAK, 2003, p. 92) onde "pessoas jogam ansiosamente para poder trocar suas identidades" (ibidem, 2003, p.98) e Rachel Hutchinson 'Performing the Self' (2007) no qual ela proclama que "os jogadores sofrem um processo de identificação com o avatar tornando-se uma projeção ou imaginação do self" (HUTCHINSON, 2007, p. 288) e onde a "habilidade de escolher entre personagens à vontade, oferece oportunidade para experimentação ilimitada para múltiplos selves" (ibidem, 2007, p. 294). Por isso, a identidade jogadores-avatares se tornam fechadas dentro das estruturas de auto performance, autoconstrução e auto multiplicação caracterizada por termos como "máscaras", "múltiplos eus", "identidades virtuais", "auto projeção", "autoconsciência", "experimentação de identidades" e "jogo de identidade". Fazendo uma provocação, esse posicionamento constrói a identidade jogador-avatar como uma relação de narcisismo onde jogadores estão imersos no role playing ou na performance deles mesmos como avatares.

\section{Introduzindo o prazer pelo fazer}

A revisão e exposição feitas em cima de pesquisas sobre identidade jogador-avatar são obviamente uma leitura provocativa e superficial. No entanto, é justificável, como a ampliação das tendências subjacentes, podem ajudar a expandir e esclarecer as correntes existentes dentro da área de pesquisa. Enquanto todos os cinco posicionamentos possuem uma fundamentação e relevância; por exemplo a relação jogador-avatar compreendida através da perspectiva dramatúrgica dentro do explícito role playing, ou da relação jogadoravatar compreendida como uma construção cognitiva dentro dos explícitos jogos de quebra cabeça, é, entretanto, problemático que de modo geral pesquisas não se preocupem com ou atentem para a conexão corpórea, como uma dimensão fundamental e fundacional na identidade de jogadores-avatares. Assim sendo, o artigo irá na sequência tentar esclarecer esse sexto posicionamento: a identidade jogador-avatar como uma conexão corpórea. Isso é feito, novamente, ao mover através dos posicionamentos típicos dentro da identidade jogador-avatar, mas agora com a perspectiva explicitamente fundada na corporalidade e locomoção, portanto, possibilitando uma movimentação global: 
a) de imagens corporais para esquemas corpóreos e de perspectivas visuais para 'perspectiva tátil4';

b) de transmissão instrumental intencional para locomoção corpórea e de mentes projetadas para memória corporal;

c) de role-playing, presença e performance para digital corporalidade;

d) de extensão corporal, protética e ferramentas extensoras para incorporação corpórea, manufaturado e ferramentas implementadas manualmente/artesanal;

e) de auto representação e jogo de identidade para auto-ser (self-being) e auto-fazer (self-doing)

Por adoção e adaptação filosófica, e trabalhos teóricos com corporeidade, locomoção, interação digital e habilidade torna-se possível transformar e revirar as construções impregnadas da identidade jogador-avatar. Desse modo, cada posicionamento será filtrado através da "perspectiva corpórea" e adicionada a contraparte corpórea que quando combinada irá construir a conexão corpórea na identidade jogador-avatar.

\subsection{Corporalidade digital: esquema corpóreo e 'perspectiva tátil'}

Dentro dessa primeira perspectiva, "Visualidade: Identidade Jogador-Avatar como Imagem Corporal e Perspectiva Visual", a conexão jogador-avatar foi construída como uma relação de voyeurismo da percepção visual e da perspectiva visual. Na sequência dois aspectos centrais desse argumento serão destacados (ou estarão em foco): a imagem corporal e a perspectiva visual.

\subsection{De imagem corporal para esquema corpóreo}

Cabe destacar que, o conceito de imagem corporal deve ser distinguido do conceito de esquema corpóreo, especialmente desde que o "esquema corpóreo" de Maurice MeleauPonty vem sendo traduzido de modo pouco cuidadoso para "imagem corporal". Como Shaun Gallagher menciona:

[...] uma distinção clara entre imagem corporal e esquema corpóreo é absolutamente necessário, se esses termos servem para qualquer finalidade útil [...]

${ }^{4}$ No original: "handsight" 
A diferença entre imagem corporal e esquema corpóreo é como a diferença entre ter uma percepção de (ou crer sobre, ou uma atitude emocional sobre) o próprio corpo e ter a capacidade de movimentar o próprio corpo (GALLAGHER, 2003, p. 234, ênfases no original).

Portanto, o esquema corpóreo é o modo que os jogadores têm para conhecer seus corpos (como jogadores-avatares) em ação/atividade; é o seu foco corpóreo, no jogo que está em mãos (na sua frente). De acordo com o conceito de esquema corpóreo, jogadores conhecem a si mesmos como avatares através da ação corpóreo-locomotiva que eles realizam. Na base do esquema corpóreo, a conexão com avatar é significativa por conta daquilo que os jogadores são capazes de fazer, e não por conta daquilo que os jogadores são capazes de parecer ou para o que são capazes de olhar. Consequentemente, a conexão avatariana é mais uma questão de capacidade corpóreo-locomotiva do que percepção visual ou aparência. De acordo com o conceito de esquema corpóreo de Merleau-Ponty, jogadores são corpos que possuem uma conexão com o mundo interno e pré reflexivo entre corpo e mundo. 0 esquema corpóreo é, portanto, um modo que os jogadores possuem, conhecem e fazem sentido de seu corpo, enquanto corporalidade digital em ação, dentro do mundo do jogo material-digital. Assim, temos no centro da identidade de jogadores-avatares, uma conexão fundamental entre sentido (significado) no mundo do jogo material-digital e o fazer corporalidade digital nesse mundo de jogo. Em outras palavras, a identidade jogador-avatar torna-se os feitos do jogador como corpo corpóreo e digital fundidos dentro da unidade das estruturas esquemáticas do corpo dinâmico dos jogadores.

Isso é um longo caminho para a identidade jogador-avatar de Rehak e Filiciak, como uma relação com a imagem corporal, na qual os jogadores tornam o avatar um fetiche visual, onde há o desejo de ser visto e ver a si mesmos - uma estrutura de desejo voyeurístico, onde o desejo dos jogadores pela “'refletividade' perfeita, isso é, uma que relembre a visualidade dos jogadores e (assim como em um espelho) parece olhar de volta para ele ou ela" (REHAK, 2003, p. 107). Porém, o desejo de longa história dos videogames claramente mostra a impossibilidade (ibidem, 2003). Entretanto, com o advento EyeToy Camera, para PlayStation 3, esse desejo foi inesperadamente realizado. Em Move: Start the Party, as imagens corporais dos jogadores são perfeitamente representadas visualmente no espaço digital, olhando de volta para os jogadores e espelhando todos os seus movimentos. Então, por que os jogadores normalmente não se sentem mais intimamente conectados com suas imagens espelhadas e visualmente "impecáveis", do que aquela que possuem para seus avatares "falhos" de WoW? Isso é, provavelmente, devido ao fato de que os jogadores não se 
conectam aos avatares primeiramente como 'saídas visuais perceptíveis', porém mais como uma 'interação vivenciada pela corporalidade digital'. Para os jogadores, a identidade jogador-avatar é causada pela íntima conexão avatariana com a expressividade corpóreolocomotiva dos jogadores. Por isso, a conexão avatariana não é uma relação de desengajamento ou destacamento corpóreo, como Rehak teria dito: "Nós criamos avatares para deixar nossos corpos para trás". (ibidem, 2003. p. 123) Ao invés disso, é uma relação de engajamento e ligação corpórea e, por isso, de acordo com o que James Newman diz: "O que estou dizendo é que o prazer de jogar videogame não é primariamente visual, mas em vez disso kinestésico". (NEWMAN, 2002, sem numeração e com ênfase no original) A identidade jogador-avatar se desdobra no esquema corpóreo, onde a distinção entre avatares e jogadores é dissolvida, à medida que, a fusão corpórea entre jogador-avatar tem precedência sobre a distinção visual jogador-avatar. Jogadores são engajados corporalmente em avatares (independente de sua aparência), e avatares são absorvidos dentro do esquema corpóreo dos jogadores (como capacidades esquemáticas de esquemas corpóreos). Jogadores e avatares tornam se unidades dinâmicas de interação onde aprender a jogar como jogador-avatar é para enriquecer o esquema corpóreo e adquirir uma nova possibilidade digital-locomotiva através da locomoção corpórea - Os avatares de Borderland, WoW e Move: Start the Party são instanciações específicas de estruturas de esquema corpórea. Portanto, a identidade jogador-avatar em $W o W$, se torna o crescimento e a modelagem de um corpo de jogo de $W o W$, onde a identidade existe dentro e através das mãos dos jogadores, e apenas surgem através do empenho corpóreo. Implicando dizer que a identidade jogador-avatar não pode ser compreendida ou formulada sem esse esforço. A razão pela qual jogadores investem em si mesmos e em seus avatares, seja em $W o W$ ou em Move: Start the Party, é porque avatares são expressões de suas competências esquemáticas corpóreas e trabalho corpóreo. Desse modo, pode-se até argumentar que uma forte identificação com um avatar em WoW é significado de milhares de horas de interação corpórea, do que com o perfeito avatar espelhado encontrado em Move: Start the Party. Avatares são, portanto, não tanto como imagens corporais de jogadores ou dublês corporais, percebidos como saídas visuais, visto que eles são esquemas corpóreos de jogadores em ação. Consequentemente, a identidade jogador-avatar torna-se uma estrutura corpórea de engajamento em primeira pessoa, do que percepções visuais voyeurs - conduzindo para outra área central dentro da visualidade; ou seja, o conceito de perspectiva visual. 


\subsection{De perspectiva visual para a perspectiva tátil}

Em pesquisas, existe uma correlação entre construir jogador-avatar como uma relação fundada na imagem corporal, caracterizando a força da identificação do jogador como dependente da perspectiva visual. Desse modo, Martthi Lahti, Bob Rehak, Alison McMahan, assim como, Cathy Cleland privilegiam a perspectiva visual em "primeira pessoa" como sendo: a mais "imersiva" ${ }^{5}$ (MCMAHAN, 2003, p. 67); a "corporificada" ${ }^{6}$ (CLELAND, 2010, p. 85); a "subjetiva e unificadora" 7 (LAHTI, 2003, p. 161); e como causa da "imersão corpórea" e "imersão sensória" 8 (REHAK, 2003, p. 118). Portanto, todas elas concordam com o fato de que: "Diferentes articulações entre câmera-corpo e avatar-corpo levam a diferentes, embora relacionados, modos de jogar e efeitos individuais". (REHAK, 2003, p. 109)

Porém, se a relação jogador-avatar está fundada na estrutura de esquema corpóreo, do que em imagem corporal, essa perspectiva precisa ser reformulada, visto que, a interação corpórea tem relação com o grau de imersão experimentado, unificação e subjetividade. Assim, a interação corpórea em primeira pessoa de jogadores com os dispositivos de entrada materiais faz com que a perspectiva visual seja sempre de primeira pessoa como se "o corpo é de fato 'o sujeito natural de percepção' e o 'ponto de vista dos pontos de vista'" (CASEY, 1987, p. 147). Ou, nas palavras de James Newman:

\section{[...]para o jogador principal, no entanto, o ponto de vista é importante apenas na medida em que afeta o jogo [...] durante o jogo online, videogames são experimentados em primeira mão pelo jogador principal independente do modo de sua apresentação ou conteúdo mediado (NEWMAN, 2002, sem paginação).}

A descrição de conexão corpórea em ação na perspectiva dos jogadores no jogo de tiro em 'primeira pessoa' Bordelands, e do MMOG de 'terceira pessoa' WoW , é possível pela adaptação do relato de Mark B.N. Hansen sobre obra digital 'Handsight' in 'Bodies in Code' (2006). Ao dar um passo atrás da tela e observar como a "perspectiva visual" é criada através da interação corpórea, é possível compreender como a interação corporalidade digital de jogadores torna a diferença entre perspectiva em primeira-pessoa e terceirapessoa insignificante. Jogadores de Borderlands e WoW experimentam de modo semelhante a perspectiva de primeira-pessoa, devido a sua interação em primeira-pessoa com os dispositivos materiais de entrada, pelos quais eles criam e controlam seus pontos de vista

\footnotetext{
5 No original: "immersive".

${ }^{6}$ No original: "embodied".

${ }^{7}$ No original: "subjective and unifying".

${ }^{8}$ No original: "corporeal immersion" e "sensory immersion".
} 
visual. Ao olhar para a corporalidade dos jogadores, e não apelas para a saída visual, tornase mais claro como jogadores em Borderlands, assim como em WoW veem digitalmente através da interação corpórea enquanto eles navegam incessantemente o campo visual através das interações corpóreas com o mouse ou teclado. Assim, o olhar tradicional (perspectiva visual) é transformado em 'perspectiva tátil' (navegação corpórea em primeira-pessoa) direcionando a perspectiva visual através da interação corpórealocomotiva dos jogadores com suas mãos. Consequentemente, WoW, assim como muitos outros jogos, implementam a presença tácita da primeira-pessoa no campo visual através do "acoplamento transdutor de visão e toque" (HANSEN, 2006, p. 81), como a visão digital é mapeada na locomoção corpórea. Borderlands e WoW exigem que os jogadores iniciem e naveguem a operação de visão através da mão, e assim, ao direcionar a função de visão pela manipulação manual, os jogos fazem o usuário "ver com as mãos". Desse modo, o espaço digital não pode ser compreendido como um espaço visual e a perspectiva não pode ser compreendida de acordo com a saída visual. Ao invés disso, a perspectiva é criada pela ativa e proativa locomoção corporal. Como resultado, 'perspectiva tátil' tem precedência sobre a 'visão' pois, tanto Borderlands, quanto WoW exigem que os jogadores desenvolvam 'perspectiva tátil' em primeira-pessoa.

De modo geral, jogadores competentes percebem visualmente suas interações avatarianas no espaço digital com mais habilidade do que novatos, precisamente porque eles aprenderam a fundir a digitalidade na tela com a corporeidade fora da tela; eles podem ver na tela como eles devem agir fora da tela, e eles sabem como eles devem agir fora da tela para atuar na tela. Portanto, jogadores competentes enraizaram com habilidade sua conexão avatariana na corporalidade e esse enraizamento se manifesta sob a forma de uma fusão corporalidade digital na qual os jogadores vivenciam a esfera digital diretamente através da visão em primeira-pessoa e agência em primeira-pessoa, interagindo simultaneamente de maneira corpórea e digital no mundo de jogo, seja em Borderlands, em WoW ou em Move: Star the Party. Nessa versão da conexão avatariana fundamentada no esquema corpóreo e na perspectiva tátil, a geração da perspectiva em primeira-pessoa, a imersão e o engajamento não são obtidos pela simulação de imagens e perspectivas visuais do corpo, mas pelo estímulo à locomoção corpórea. 


\subsection{Locomoção corporal e memória corporal}

A fundamentação para a conexão corpórea na identidade jogador-avatar se estabeleceu ao substituir a imagem corporal pelo esquema corpóreo e a visão pela perspectiva tátil. Isso, no entanto, é insuficiente se alguém quiser entende a identidade jogador-avatar como uma conexão corpórea. Portanto, o artigo agora se volta para os posicionamentos cognitivos na tentativa de compreender a interação esquemática corporal no jogo, não como ações instrumentais transmitindo intencionalidade cognitiva ao avatar, mas como fluxos kinestéticos inerentemente significativos da locomoção. Além disso, a identidade jogador-avatar será descrita como uma relação armazenada e renomeada como memória corporal, e não como uma consciência cognitiva sob a forma de mentes projetadas e corporificadas.

Dentro desse segundo argumento, “Cognição: identidade jogador-avatar como mentes projetadas e transmitidas intencionalmente", a conexão jogador-avatar foi construída como uma relação mental de jogadores como mentes projetadas, corporificadas e imersas em avatares digitais, ou como intencionalmente cognitivas que se desdobram na esfera digital pela transmissão de cognição para os avatares através de ações corpóreas instrumentais. Na sequência duas áreas centrais seguintes desse argumento serão abordadas: intencionalidade cognitiva, e mentes projetadas e incorporadas.

\subsection{Da Transmissão Instrumental/Intencional para Locomoção}

Ao invés de construir as ações e movimentos corpóreos como meros meios para uma finalidade (cognitiva), o modelo de Richard Sennett 'O Artífice' (2009) e Maxime SheetsJohnstone 'The Pimacy of Movement' (1999) nos permitem compreender a locomoção corpórea como inerentemente expressiva, significativa e influente. De acordo com Sennett, habilidade artesanal corpórea é "a capacidade de fazer bem as coisas" (SENNETT, 2009, p. 19) desdobrando como uma conexão íntima entre cabeça e mão em que pensar, ver e sentir 
estão incorporados e contidos dentro das mãos do artífice". Desse modo: "O artífice representa uma condição humana especial: a do engajamento. Um dos objetivos deste livro é explicar como as pessoas se engajam de uma forma prática, mas não necessariamente instrumental." (SENNETT, 2009, p. 30). Consequentemente, o trabalho manual corpóreo (por exemplo a interação corpórea dos jogadores com os dispositivos materiais de entrada) nunca é apenas um meio para um fim - ao invés disso é sempre parte de um fim. Entretanto, uma abordagem fundamentada na intencionalidade cognitiva instrumental é incapaz de revelar a qualidade experiencial da fusão da locomotividade corpórea dos jogadores com a locomotividade digital para os avatares. Seguindo Sennett, a locomoção corpórea em WoW não pode ser significativamente dividida em atos motores instrumentais separados, por exemplo, pressionando a tecla 1 e então a tecla 2 a fim de realizar as intenções cognitivas de fazer o avatar lançar um 'flash heal' e, em seguida, uma 'greater heal' em um ataque de WoW. Ao invés disso, a identidade jogador-avatar emerge das inseparáveis correntes kin-estéticas da locomoção corpórea dos jogadores fundida com a locomoção digital dos avatares. Implicando que a identidade jogador-avatar é baseada na união corporalidade digital e digital corporalidade dos esquemas corpóreos unificados dos jogadores à medida que os jogadores desenvolvem e obtêm prazer de suas aptidões de habilidade, em vez de se basear na transmissão de suas mentes pensantes.

Em a 'Primacy of Movement' (1999) Maxine Sheets-Johnstone põem em primeiro plano a locomoção corpórea afirmando que: "Claramente, o movimento em um sentido bastante literal informa a percepção" (SHEETS-JOHNSTONE, 1999, p. 183). De acordo com essa perspectiva, os jogadores conhecem seus avatares relacionando-se à sua locomoção corpóreo-digital. Em jogos de computadores a locomoção corpóreo-digital necessariamente está em ação em cada relação jogador-avatar: “Em suma, quaisquer que sejam as diferenças, o movimento é nossa linguagem nativa" ${ }^{10}$ (ibidem, 1999, p. 226). Em Borderlands, em WoW e em Move: Start the Party a locomoção corpórea dos jogadores é o que estabelece e sustenta suas conexões avatarianas; os jogadores podem apenas "se tornar" avatares ao deixarem

\footnotetext{
${ }^{9}$ Nota de tradução: No original Sennett (2009) usa o termo craftsman e a tradução para o português brasileiro - tradutor Clovis Marques - como artífice. Segue um trecho com a definição do termo: "O artífice explora essas dimensões de habilidade, empenho e avaliação de um jeito específico. Focaliza a relação íntima entre a mão e a cabeça. Todo bom artífice sustenta um diálogo entre práticas concretas e ideais; esse diálogo evolui para o estabelecimento de hábitos de prolongados, que por sua vez criam um ritmo entre a solução de problemas e a detecção de problemas. A relação entre a mão e a cabeça manifesta-se em terrenos aparentemente tão diferentes quanto a construção de alvenaria, a culinária, a concepção de um playground ou tocar violoncelo - mas todas essas práticas podem falhar em seus objetivos ou em seu aperfeiçoamento. A capacitação para a habilidade nada tem de inevitável, assim como há de descuidadamente mecânico na própria técnica." (SENNET, 2009, p.20, grifos no original)

${ }^{10}$ No original: "In sum, whatever our differences, movement is our mother tongue".
} 
fluir a locomoção corpórea das mãos deles. Desse modo, a identidade jogadores-avatares nunca é ainda nascida, mas sempre "nascida em movimento" ${ }^{11}$ (ibidem, 1999, p. 244). Esse reconhecimento e atenção à locomoção corpórea é essencial, pois destaca o fato de que os jogadores só podem experimentar uma conectividade avatariana através da locomoção corpórea. Quando jogadores-enquanto-avatares se aventuram em um ataque em WoW eles estão envolvidos em uma locomoção corpórea, implicando que, na identidade do jogadoravatar, como na dança "não há 'fazer mental' que é separado do 'fazer corporal"' ${ }^{12}$ (ibidem, 1999, p. 487). Jogadores de WoW se integram com seus avatares no esquema corpóreo de acordo com os padrões de locomoção corpórea que o jogo coloca à disposição. Consequentemente, a conexão e identificação que os jogadores têm com as formas como os avatares são incorporados nas mãos dos jogadores através da locomoção corpórea como um "pensamento em movimento" 13 (ibidem, 1999, p. 485). Essa conexão e experiência avatariana locomotiva-corpórea é kin-esteticamente diferente, mas em pé de igualdade, com as conexões e experiências avatarianas corporais-locomotivas encontradas em Borderlands e Move: Start the Party. Todos os três jogos possuem seus próprios modos de fazerem os jogadores dançarem na batida do jogo. Por isso, a identidade jogador-avatar dentro desses jogos significa "de modo quase literal [...] vindo a enfrenta-lo - explorando-o, pesquisando-o, descobrindo-o através do movimento" (ibidem, 1999, p. 226); jogadores são unidades mais corpóreo-digitais em movimento, do que mentes pensantes revelando cognição através dos avatares.

\subsection{De mentes projetadas à memória do corpo}

O primeiro plano mencionado acima sobre o esquema corpóreo dos jogadores e a interação corpórea-locomotiva também possui influência sobre como a identidade dos jogadores-avatares é adquirida, armazenada e recuperada. Ao invés de construir a identidade de jogadores-avatares como projetando, incorporando e armazenando cognição, o esquema de Edward S. Casey em 'Remembering' (1987) põem a nossa disposição um esquema para compreender a relação como um tipo de memória corporal. Como a conexão avatariana não é uma experiência fora-do-corpo, mas uma experiência no-corpo

\footnotetext{
11 No original: "movement-born".

12 No original: "mind-doing" e "body-doing".

${ }^{13}$ No original: "thinking in movement".
} 
caracterizada também por uma habilidade corpórea e locomotiva, dentro dos corpos dos jogadores, a conexão avatariana é armazenada e lembrada: “Meu corpo não apenas me leva a lugares; ele me habitua às suas peculiaridades e me ajuda a lembra-las vividamente" (CASEY, 1987, p. 180).

Quando pensamos em jogos eletrônicos que jogamos muito no passado, nós frequentemente não lembramos apenas da saída visual, dos quebra-cabeças cognitivos ou do espaço digital. As lembranças de jogos muito disputados são tão lembradas quanto padrões corpóreo-locomotivos e memórias no corpo. Os corpos dos jogadores ressoam com os movimentos corpóreos sob a forma de avatares, impressos em seus esquemas corpóreos como composições rítmicas únicas. Minhas mãos ainda se lembram de Summer Games (Epyx/U.S. Gold, 1984) para Commodore 64; como minha mão esquerda, em corrida, frenética, mas ritmicamente empurrava os controles de um lado ao outro enquanto eu corria na tela. Minhas lembranças de Summer Games são (também) memórias corpóreaslocomotivas - 0 exercício de mergulho em plataforma lembrado como o girar dos controles em um ritmo cuidadosamente medido em perfeita harmonia com minha corporeidade digital enquanto as mãos criavam um mergulho impecável do trampolim. Desse modo, os jogadores adquirem e recordam suas conexões avatarianas através da habilidade, não apenas pelas habilidades mentais (mindcraft) ou visuais (eyecraft). Consequentemente, a 'aquisição' do avatar do jogador não pode ser completamente compreendidas sem reconhecer e levar em consideração aquilo que Edward S. Casey nomeou como memória corporal: “Eu falo de 'memória corporal', não como 'memória do corpo'. Memória corporal alude à memória que é intrínseca ao corpo, às suas próprias maneiras de lembrar: como nós lembramos em, por e através do corpo" (ibidem, 1987, p. 147). A memória corporal dos jogadores é o modo como seus corpos lembram de sua própria atividade; como uma dimensão pré-reflexiva e pré-cognitiva da experiência, Casey nomeia "lembrança performativa" ${ }^{14}$ (ibidem, 1987, p. 148). Memória corpórea é uma lembrança com e através das mãos à medida que as lembranças dos jogadores (como avatares) são inscritas na locomoção corpórea. Consequentemente, é principalmente através da memória do corpo que os jogadores subsequentemente têm acesso à sua atividade de jogo, e não através de suas lembranças narrativas, "re-visão" pictórica ou armazenamento cognitivo. A memória corporal leva os jogadores "diretamente para o que está sendo lembrado" (ibidem, 1987, p.

14 No original: "performative remembering". 
167, ênfase no original) enquanto suas mãos novamente encontram seu caminho pelo teclado, mouse ou controles:

O que é particularmente impressionante não é [...] apenas o repentino e não-
premeditado retorno da memória corporal relevante - para o qual não era
necessário reaprender ou revisar expressamente -, mas o fato de não haver
nenhuma lembrança explícita de aprendizado anterior [...]. Tudo o que se pede é
que exista corpo na circunstância em que uma determinada memória corporal é
pertinente. (ibidem, p. 148)

E ainda hoje, os jogadores não jogam $W o W$ ano após ano como avatares apenas pela experiência cognitiva, social, narrativa ou visual. Eles jogam (tanto quanto) para orquestração corpórea-locomotiva do jogo; o modo como movimentam seus corpos - e a sua criação corpórea-locomotiva; o modo pelo qual eles colocam a si mesmos em movimento. Eles constroem suas conexões avatarianas através da presença e do envolvimento corpóreo e mantêm e recordam em seus corpos a memória do corpo.

\subsection{O jogador-como-avatar: digital corporalidade}

Entretanto, para que a conexão corpórea faça sentido, não é suficiente uma explicação do jogador corpóreo conectando-se ao avatar através do esquema corpóreo, de perspectiva tátil, da locomoção, e mantendo a conexão pela memória corpórea. Na identidade jogadoravatar, a conexão ocorre nos dois sentidos; do jogador ao avatar e do avatar ao jogador. Nos jogos, os jogadores estão concorrendo como 'jogadores-como-avatares' $e$ como 'avatarescomo-jogadores'. Portanto, o artigo se volta para a dramaturgia numa tentativa de enquadrar os jogadores, não como atores imersos em personagens ficcionais em mundos fictícios através do role-play ou faz de conta, mas como 'interatores' imersos na fusão da corporalidade digital e digital corporalidade através da interação corpóreo-digital.

Dentro desse terceiro posicionamento, "Dramaturgia: Identidade Jogador-Avatar como Role-Play, Presença e Performance", a conexão jogador-avatar foi enquadrada como uma relação de escapismo dos jogadores como atores imersos no role-playing e pretendendo ser os avatares digitais. A seguir, essa área central será abordada pelo conceito de digital corporalidade. 0 conceito de digital corporalidade destina-se a capturar o jogadorcomo-avatar; isso é, as encarnações digitais de jogadores (seres em tela) e interações (ações em tela) constituem a versão digital de sua experiência no corpo. 


\subsection{De role-playing, pretensão e performance para digital corporalidade}

Em vez de enquadrar as interações digitais avatarianas como role-playing e faz de contas, o artigo irá, a seguir, com base em uma instigante citação de James Newman, tentar entender os jogadores-como-avatares como corporalmente criados, imersos, e modelados digitalmente, do que imersos dramaticamente em role-playing e fingimentos. De acordo com Newman, a relação de jogadores com avatares é diferente da relação de espectadores/leitores/público com personagens em filmes/textos/encenações: "No cartum, Sonic possui autonomia e independência. Resumindo, ele tem caráter [...] São faz sentido falar de Sonic como "ele" nesse mundo além do videogame online. No jogo, "Sonic" torna-se a habilidade de correr rapidamente, rolar e recolher anéis" (NEWMAN, 2002: não paginado). Seguindo esse pensamento, a identidade jogador-avatar em por exemplo WoW não depende da representação ou empatia dramatúrgica, mas em possibilidades e agenciamentos interacionais, na medida em que: “'personagem' é concebido como capacidade - um conjunto de características". (ibidem, 2002: não paginado) Quando jogadores jogam WoW, eles criam o jogo por meio da locomoção corpórea, mas essa criação corpórea é, mais importante, moldada pela padronização do jogo de sua corporalidade digital. Em WoW, Borderlands e Move:Start the Party, as conexões e os padrões entre jogadores-como-avatares e o espaço digital, assim como a interface digital e a material, suportam e promovem certos tipos de interações corpóreo-digitais e desconsideram ou desestimulam outros tipos de interações corpóreo-digitais. Nas palavras de Dovey e Kennedy:

\footnotetext{
0 jogo sinaliza sua dependência no jogador como (exceto durante as cut scenes) o avatar não se moverá sem alguma ação [corpóreo-locomotiva] por parte dos jogadores. Significativamente, porém, é preciso enfatizar que as capacidades, os limites e as possibilidades codificadas nos nossos avatares também determinam o alcance e a forma como nossas atividades - ações e reações são interdependentes, com agência fluindo através da conexão em um loop de feedback. (ibdem, 2006, p. 109)
}

Dessa forma, a entrada corpórea-locomotiva dos jogadores é moldada pelas capacidades e possibilidades codificadas dos avatares, assim como os padrões materiais e digitais dos jogos. Combinados, esses fatores constituem a digital corporalidade dos jogadores. Entretanto, a digital corporalidade não se enquadra nos títulos da imagem corporal, aparência, representação ou role-play. A digital corporalidade não é a imagem corporal ou o personagem fictício na tela dos jogadores, mas suas estruturas esquemáticas do corpo digital. Para os jogadores, geralmente importa mais como sua digital corporalidade 
interaciona e esquematicamente corporeamente se manifesta, do que como é representado visualmente como imagem corpórea, ou dramaticamente como personagem ficcional. 0 que importa aos jogadores-como-avatares é embutir seu esquema corpóreo avatariano digital dentro do seu esquema corpóreo corporal. Desse modo, jogadores-como-avatares são corporalmente mais imersos do que dramaticamente imersos, como os competentes jogadores de $W o W$ durante um ataque podem comprovar. Aqui, não há tempo para role-play ou faz de conta, enquanto os jogadores tentam enraizar sua digital corporalidade em sua corporalidade digital, à medida que, eles interagem simultaneamente digitalmente e corporalmente no mundo do jogo. Não enquanto personagens fictícios em faz de conta, mas como jogadores-avatares corporalmente esquematicamente imersos e envolvidos em reais interações corpóreo-digitais. O jogador-como-avatar é um corpo em movimento no ambiente digital quando o corpo se move na esfera corpórea. Desse modo, a digital corporalidade dos jogadores-como-avatares é fundida com sua corporalidade digital de tal modo que torna se impossível ou sem sentido diferenciar entre ou questionar onde o jogador que interage corporalmente e o avatar que interage digitalmente começa ou termina. Incorporar o avatar como digital corporalidade é, para os jogadores, o modo normal de se relacionarem com avatares; não há fazer-avatar delimitadas de fazer-jogador. Consequentemente, torna-se necessário incluir a conexão corpórea ao investigar jogadorescomo-avatares, pois é necessário incluir a conexão digital ao investigar avatares-comojogadores.

\subsection{O avatar-como-jogador: incorporação corpórea e habilidade}

A consideração acima dos jogadores-como-avatares e da digital corporalidade dos jogadores precisa finalmente ser conectada com os avatares-como-jogadores e a corporalidade digital dos jogadores, a fim de esclarecer completamente a conexão corpórea na identidade do jogador-avatar. No entanto, como ficará claro a seguir, a corporalidade digital não é alcançada por meio de interação e de extensão protética, nem por meio do uso de ferramentas protéticas e de extensão. Portanto, a fim de esclarecer a identidade do jogador-avatar como uma experiência incorporada no corpo, o artigo se volta para a postura protética na tentativa de enquadrar a corporalidade digital e o avatar-como-jogador, não como extensão protética centrífuga da corporeidade para a digitalidade, mas como a 
handcrafting incorporação centrípeta da digitalidade na corporalidade. Não é um caso de jogadores assumirem o papel de um manipulador de marionetes, controlando remotamente o boneco-avatar, nem um caso de jogadores sendo condutores dirigindo seu avatar "de dentro". Em vez disso, os avatares são implementados dentro dos esquemas corpóreos dos jogadores.

\subsection{De extensão corpórea, próteses e ferramentas de extensão para incorporação corpórea e habilidade}

Em vez de enquadrar as interações corpóreas como extensões protéticas ou uso de ferramentas, esse artigo irá, através Richard Sennett 'O Artífice' (2009), construir a corporalidade digital de avatares-como-jogadores enquanto presença corpórea e incorporando habilidade. Enquadrar a identidade de jogadores-avatares como extensão protética e uso de ferramenta está em certa medida, de acordo com a descrição de MerleauPonty da utilização de ferramentas; próteses notáveis e a bengala do cego. Portanto, é uma perspectiva um tanto relacionada com a visão apresentada aqui. Entretanto, existem diferenças importantes entre como a corporeidade e o uso de ferramentas dos jogadores são enquadradas na "conexão corpórea" e na "conexão protética". A diferença reside parcialmente nas metáforas usadas para descrever a corporalidade e o uso de ferramentas dos jogadores. Enquanto a última visão implanta "ferramentas de extensão", como o bisturi ou a bengala de um homem cego, a primeira implanta como "ferramentas de implantação", como guitarras ou esquis. Na última visão, os jogadores se estendem e se sentem no final da ferramenta, enquanto os jogadores na visão anterior implantam a ferramenta e a sente como parte de si mesmos. Essas duas visões de ferramentas são consistentes com a distinção entre o uso da ferramenta "na ponta dos dedos" e o uso da ferramenta "no final da ferramenta" como encontrado em 'O Artífice': "Na mão, como vimos, essa localização está na ponta dos dedos do músico ou do ourives; no olho, a localização centra-se no ângulo reto formado pela trama e a urdidura no tear, ou no fim do tubo usado para insuflar vidros" (SENNETT, 2009, p. 310).

Optar por ver a corporalidade digital na identidade jogador-avatar como mais alinhada a tocar música, do que com o uso de próteses, nos permite enquadrar a identidade jogador-avatar como uma incorporação esquemática do corpo centrípeto do que uma 
extensão centrífuga protética. Assim como as guitarras tornam se parte do corpo dos músicos e a guitarra torna se incorporada nos esquemas corpóreos dos músicos, a interface e os avatares em WoW se tornam partes dos corpos dos jogadores de WoW e jogar WoW se torna incorporado no esquema corpóreo dos jogadores de WoW. Músicos e jogadores de WoW não fazem das guitarras ou das interfaces/ dos avatares extensões protéticas de seus corpos; em vez disso, eles incorporam guitarras e interfaces/avatares em seus corpos e os implementam como partes inerentes de seus corpos de jogo. Por isso, os jogadores não são transplantados ou estendidos para as ferramentas que usam (como bisturis ou bengalas) mas implementados ou incorporados em seus corpos corpóreo-locomotivos. Avatares residem dentro do esquema corporal de jogadores; em WoW eles existem nas mãos dos jogadores e não na ponta de suas ferramentas. Assim, jogadores são, sob esse ponto de vista, não mais manipuladores de marionetes, mas corporalmente ocupados e engajados em incorporar perspectivas e agência de primeira-pessoa em seu único corpo de primeira-pessoa. A identidade jogador-avatar é expressa e experimentada como presença corpórea, ao invés de extensão corporal, onde "Movimentos duramente conquistados se tornaram cada vez mais arraigados no corpo; o jogador se torna melhor" (SENNETT, 2008, p. 160). A corporalidade digital é uma habilidade artesanal enquanto uma atividade exemplar, na qual jogadores esculpem avatares na esfera digital, atraindo-os para a esfera corpórea com suas mãos elaboradas. Desse modo, a conexão avatariana não é uma experiência tecnologia-dentro ou corpo-dentro, mas uma experiência corporal; onde a conexão avatariana está contida dentro no processo de criação. Como resultado, ocorre uma fusão esquemática corporal entre jogadores-como-avatares e avatares-como-jogadores, tornando o avatar parte do corpo do jogador e não ao contrário. Consequentemente, a identidade jogador-avatar é mais o caso de implosão digital na corporeidade do que de explosão corporal na digitalidade.

\section{0 prazer pelo fazer como uma fusão: auto-ser (self-being) e auto-fazer (self-doing)}

Os componentes para a conexão corporal foram reunidos e em conjunto, eles constituem uma identidade de jogador-avatar expressa como auto-ser (self-being) e autofazer (self-doing), ao invés de auto representação ou identidade. Abaixo temos um sumário 
contendo os elementos principais da conexão corporal, bem como suas contrapartes padrões.

Quadro 1 - Esquema visual do prazer pelo fazer como uma fusão do auto-ser (self-being) e auto-fazer (self-doing)

\begin{tabular}{|c|c|c|c|c|}
\hline \multicolumn{5}{|c|}{ Enquadramentos Padrões da Identidade Jogador-Avatar } \\
\hline $\begin{array}{l}\text { Visualidade: } \\
\text { Imagem Corporal } \\
\text { Eyesight } \\
\text { (Perspectiva } \\
\text { visual) }\end{array}$ & $\begin{array}{l}\text { Cognição: } \\
\text { Transmissão } \\
\text { Intencional, } \\
\text { Ações } \\
\text { Instrumentais } \\
\text { Incorporação } \\
\text { Projetada, } \\
\text { Cognição } \\
\text { armazenada }\end{array}$ & $\begin{array}{l}\text { Dramaturgia: } \\
\text { Role-Play, } \\
\text { Pretensão, } \\
\text { Performance }\end{array}$ & $\begin{array}{l}\text { Prótese: } \\
\text { Próteses, } \\
\text { Extensões } \\
\text { Corporais, } \\
\text { Ferramentas de } \\
\text { extensão }\end{array}$ & $\begin{array}{l}\text { Sociabilidade: } \\
\text { Auto } \\
\text { Representação, } \\
\text { Identidade de jogo }\end{array}$ \\
\hline \multicolumn{5}{|c|}{ Conexão Corpórea na Identidade Jogador-Avatar } \\
\hline $\begin{array}{l}\text { Esquema } \\
\text { Corpóreo, } \\
\text { Perspectiva tátil } \\
\text { (Corporalidade de } \\
\text { primeira-pessoa) }\end{array}$ & $\begin{array}{l}\text { Correntes kin- } \\
\text { estéticas de } \\
\text { locomotividade } \\
\text { corpórea, } \\
\text { Memória Corporal }\end{array}$ & $\begin{array}{l}\text { Digital } \\
\text { corporalidade, } \\
\text { Locomoção } \\
\text { digital, } \\
\text { Jogadores- } \\
\text { como-avatares }\end{array}$ & $\begin{array}{l}\text { Corporalidade } \\
\text { digital, } \\
\text { Incorporação } \\
\text { Corpórea, } \\
\text { Habilidade, } \\
\text { Avatares-como- } \\
\text { jogadores }\end{array}$ & $\begin{array}{l}\text { Auto-ser (self- } \\
\text { being), auto-fazer } \\
\text { (self-doing), } \\
\text { Jogadores-como- } \\
\text { avatares-como- } \\
\text { jogadores }\end{array}$ \\
\hline
\end{tabular}

Fonte: Elaborado pela autora.

Claro que jogadores podem escolher assumir a posição de voyeurismo visual, mentalismo cognitivo, escapismo dramático, ciborgue protético ou narcisismo social em relação aos seus avatares, mas o "posicionamento padrão" ou a "atitude natural" com a identidade jogador-avatar é a emergencia da conexão corpórea através do prazer de autoser (self-being) e auto-fazer (self-doing). Quando jogadores jogam em Borderlands, WoW ou Move: Start the Party eles se tornam jogadores-como-avatares-como-jogadores; eles movimentam suas mãos assim como eles se movimentam na tela. Sempre que eles quiserem fazer algo acontecer como avatares no espaço digital, eles precisam agir como jogadores no espaço corpóreo. Jogadores-como-avatares-como-jogadores são fundamentalmente caraterizados, não por habitar, mas por serem corpos corpóreo-digitais habitando o mundo de jogo. Isso implica, que jogar WoW é uma atividade experimentada (também) como uma atividade corpórea - uma atividade onde jogadores-como-avatares-como-jogadores estão corporalmente engajados e que depende de sua interação corpórea para que faça sentido. Consequentemente, a identidade jogador-avatar é, para os jogadores, uma conexão corpórea profundamente envolvente, expressiva e significativa, já que eles, seguindo Sennett, são 
artífices estéticos dizendo: "Eu fiz isso", "Eu estou aqui, nesse trabalho" (SENNETT, 2009, p. 149).

Há apenas uma 'identidade' interagindo nos ataques de WoW, sessões de Borderland, e competições de Move: Start the Party que é a identidade unida de jogadores-como-avatarescomo-jogadores; uma unidade experimentada como auto-ser (self-being) e expressa como auto-fazer (self-doing). De fato, isso é uma relação muito mais cativante (e perigosa), do que a auto representação social ou jogo de identidade, visto que:

[...] a inadequação do desempenho pessoal dói de forma diferente das desigualdades de posição social ou das manifestações exteriores de riqueza: somos nós que estamos em questão. A iniciativa é sempre positiva, mas perseguir ativamente o bom trabalho e constatar que não podemos fazê-lo mina nossa identidade própria. (SENNETT, 2009, p. 113)

Nos ataques de WoW o peso (a responsabilidade) está em mim como auto-ser (selfbeing) jogador-avatar e minhas habilidades de auto-fazer (self-doing) para expressar habilidosamente meu conhecimento manual através da interação corporal e expressar como uma interação digital avatariana - uma circunstância, também presente na descrição inicial do jogador de WoW enquanto ele expressa sua identidade jogador-avatar como uma unidade de auto-ser (self-being) e auto-fazer (self-doing) em ação e vivenciando o prazer (e a ansiedade) do (auto-)fazer no centro da identidade jogador-avatar. No jogo e no centro da identidade jogador-avatar está, de acordo com Casey: "O corpo vivido como o centro que se recusa ser descentrado, a barreira central que não quer se tornar periférica". (ibdem, 1987, p. 179)

Esse artigo tentou capturar e estabelecer a conexão corpórea em jogo na identidade jogador-avatar ao destacar "essas coisas que nós podemos conhecer se nós dermos ouvidos ao corpo" (ALLEN-COLLINSON e HOCKEY, 2009) através da incorporação da construção corpórea-locomotiva. Adotar uma nova estrutura, como a corporeidade, locomotividade e incorporar a habilidade artesanal dentro da pesquisa sobre a conexão avatariana apresenta a possibilidade de ver a identidade jogador-avatar sob uma perspectiva mais completa. Além disso, apresenta a possibilidade de escapar do "imperialismo teórico" ${ }^{15}$ que Espen Aarseth (1997, p. 16) nos alerta, e contra a "hegemonia do ocularcentrismo"16 que Bryan G. Behrenshausen (2007, p. 335) se opõem. Porém, escapar pode mostrar-se difícil a medida que, o que é aplicável para estudos de esportes, infelizmente também é aplicável para pesquisas em identidade de jogadores-avatares; ou seja, o fato de que "surpreendentemente,

\footnotetext{
15 No original: "theoretical imperialism".

${ }^{16}$ No original: "hegemony of occularcentrism".
} 
dado o foco de estudo, relativamente poucas descrições são realmente fundamentadas nas realidades corporais do corpo esportivo[/gaming] vívido e sensível" (ALLEN-COLLINSON e HOCKEY, 2009, p. 71). A indagação sobre a conexão corpórea apresentada nesse artigo na identidade jogador-avatar tem, no entanto, uma tentativa de fundar a identidade jogadoravatar no vívido, sensível corpo de jogo assim como destacar como a corporalidade digital, locomotividade e habilidade artesanal não são dimensões periféricas, mas estão no centro das conexões avatarianas.

\section{Referências}

AARSETH, Espen Cybertext: Perspectives on Ergodic Literature. Baltimore: The John Hopkins University Press. 1997.

ALLEN-COLLINSON, Jacquelyn; HOCKEY, John (2009), "The Essence of Sporting Embodiment: Phenomenological Analyses of the Sporting Body,'. The International Journal of Interdisciplinary Social Sciences, vol. 4, n. 4, p.71-81. 2009.

BEHRENSHAUSEN, Bryan G. 'Toward a (Kin)Aesthetic of Video Gaming: The Case of Dance Dance Revolution'. Games and Culture, vol. 2, n. 4, p. 335-354. 2007.

BOLTER, Jay David; GRUSIN, Richard. Remediation: Understanding New Media, Cambridge: The MIT Press. 2000.

BURN, Andrew. Playing Roles. In: CARR, Diane et al. (eds.), Computer Games: Text, Narrative and Play, Cambridge: Polity Press, 2006. p.72-88.

CASEY, Edward S. Remembering: A Phenomenological Study, Indiana University Press. 1987.

CLELAND, Kathy. 'Prosthetic Bodies and Virtual Cyborgs'. Second Nature: International journal of creative media, vol. 1, n. 2, p. 72-99. 2010.

DOVEY, Jon; KENNEDY, Helen W. Gaming Cultures: Computer games as New Media, Berkshire: Open University Press. 2006.

FILICIAK, Miroslaw. 'Hyperidentities: Postmodern Identity Patterns in Massively Multiplaer Online Role-Playing Games'. In: WOLF, Mark J.P.; PERRON, Bernard (Eds.); The Video Game Theory Reader. Routledge, 2003. p. 87-103

GALLAGHER, Shaun. 'Dynamic models of body-schematic processes'. In: PREESTER, Helena De; KNOCKAERT, Veroniek (eds.), Body Image and Body Schema, Amsterdam: John Benjamins Publishing Company, 2005. p. 233-253.

GEE, James Paul. 'Video Games and Embodiment'. Games and Culture, vol. 3, n. 3-4, p. 253 263. 2008. 
GREGERSEN, Anders; GRODAL, Torben. 'Embodiment and Interface', In: WOLF, Mark J.P.; PERRON, Bernard (Eds.), The Video Game Theory Reader 2, New York: Routledge, 2009. p.65-85.

HANSEN, Mark B.N. Bodies in Code: Interfaces with digital media, New York: Routledge, 2006.

HARAWAY, Donna J. Manifesto ciborgue: Ciência, tecnologia e feminismo-socialista no final do século XX. In: TADEU, Tomaz (Org.). Antropologia do Ciborgue: as vertigens do póshumano. Belo Horizonte: Autêntica Editora, 2009.

HAYLES, N. Katherine. How We Became Posthuman: Virtual Bodies in Cybernetics, Literature, and Informatics, Chicago: The University of Chicago Press, 1999.

HUTCHINSON, Rachael. 'Performing the Self: Subverting the Binary in Combat Games'. Games and Culture, [s.l.], v. 2, n. 4, p. 283-299. 2007.

LAHTI, Martti. 'As We Become Machines: Corporealized Pleasures in Video Games'. In: WOLF, Mark J.P.; PERRON, Bernard (Eds.), The Video Game Theory Reader, New York: Routledge, 2003. p. 157-171.

LAUREL, Brenda. Computers as Theatre. Reading: Addison-Wesley Publishing Company. 1991.

MCMAHAN, Alison. 'Immersion, Engagement, and Presence: A Method for Analyzing 3-D Video Games. In: WOLF, Mark.J.P.; PERRON, Bernard (eds.), The Video Game Theory Reader, Routledge, 2003. pp. 67-87.

MERLEAU-PONTY, Merleau. Fenomenologia da Percepção. 2 ${ }^{a}$ ed. São Paulo: Martins Fontes, 1999.

NEWMAN, James. 'The Myth of the Ergodic Videogame'. Game Studies vol. 2, n. 1, 2002.

REHAK, Bob. 'Playing at Being: Psychoanalysis and the Avatar'. In: WOLF, Mark J.P.; PERRON, Bernard (Eds.), The Video Game Theory Reader, New York: Routledge, 2003. p. 103-128.

SANDVIK, Kjetil. In and Out of Character: Complex Role-play and Dramaturgy in an online World. Center for Digital Estetik-forskning, n. 14. 2006.

SENNETT, Richard. 0 Artífice. $2^{a}$ ed. Rio de Janeiro: Record, 2009. 360 pags. Tradução de Clovis Marques. ISBN: 978-85-01-08314-2. 2009.

SHEETS-JOHnSTONE, Maxine. The primacy of Movement, Philadelphia: John Benjamins Publishing Company, 1999.

STEINKUEHLER, Constance. 'Massively Multiplayer Online Games as an Educational Technology: An Outline for Research'. Educational Technology, vol. 48, n. 1, p. 10-21, 2008. 
STRAUS, Erwin. The Primary World of Senses: A Vindication of Sensory Experience, London: The Free Press of Glencoe, 1963.

TURKLE, Sherry. A vida no ecrã: a identidade na era da internet. Lisboa: Relógio d'água, 1997.

\title{
Referências Ludolográficas
}

Gearbox Software, Borderlands (2009), PC.

Supermassive Games, Move: Start the Party (2010), PlayStation 3.

Epyx/U.S. Gold, Summer Games (1984), Commodore 64.

Blizzard/Vivendi, World of Warcraft (2004), PC.

\section{The joy of doing: the corporeal connection in player-avatar identity}

\begin{abstract}
This article discusses the relation between players and avatars, on the basis of corporality, locomotion and craftsmanship. Maurice Merleau-Ponty phenomenology is the central theoretical ground, accompanied by the adaptation of frameworks from other authors for specific concepts, such as Sheets-Johnstone for corporeal locomotion and Sennet for craftsmanship. Previous studies about player-avatar identity are discussed according to 5 pervading framings: visuality, cognition, dramaturgy, prosthesis and sociality. These are reinterpreted under the guise of corporeality, leading to 6 counterpoints: corporeality, digital (corporeal scheme and visual perspective), locomotion and body memory, digital corporeality and incorporation, body extension and the joy of doing. Final remarks consider the potential of these new framings for a more complete understanding of the player-avatar identity and, also, its importance as an alternative to theoretical imperialism.
\end{abstract}

\section{Key-words}

Avatar. Corporeality. Craftsmanship. Phenomenology. Philosophy of the body. 